Revista De Filosofía

Volumen 77 (2020) 83-98

\title{
HITOS DE LA NOCIÓN DE GELASSENHEIT EN SER Y TIEMPO*
}

\author{
José Manuel Chillón \\ Universidad de Valladolid \\ España \\ josemanuel@fyl.uva.es
}

\begin{abstract}
RESUMEN / ABSTRACT
El término Gelassenheit aparece en la obra de Heidegger como temple de ánimo vinculado al modo de vida del ser humano en la época de la consumación de la metafísica, en la época técnica. Nos proponemos aquí rastrear el origen semántico del concepto de serenidad en la analítica existenciaria de Ser y Tiempo y en concreto en relación a la autenticidad, al cuidado y a la existencia cadente. Se descubre así que el trabajo de 1927 aporta las líneas decisivas de la serenidad relativas, en definitiva, a la pregunta sobre cómo se ha de soportar la existencia.

Palabras Clave: serenidad, Heidegger, cuidado, angustia, caída, autenticidad.

MILESTONES OF THE CONCEPT OF SERENITY IN BEING AND TIME

The concept of Gelassenheit appears in Heidegger's work fundamentally as temper of mind linked to the way of life of the human being at the time of the consummation of Western metaphysics, at the time of the technical age. This paper traces the semantic origin of the concept of serenity in the existential analytic of Being and Time and specifically in relation to authenticity, care and fallen existence. We will try to discover that the work of 1927 provides the decisive question of serenity: how life is to be endured.
\end{abstract}

KEYWORDS: serenity, Heidegger, care, anguish, fall, authenticity.

Introducción

$\mathbb{R A}$

La serenidad, tal y como la concibió Heidegger, responde a la cuestión sobre cómo hay que vivir ante y con la técnica que, en este momento, el nuestro, parece amenazar la propia esencia del hombre que queda en situación indigente, como se sostiene en La pregunta por la técnica. Heidegger se hace cargo del vacío del

* Este artículo se enmarca dentro del Proyecto de Investigación financiado por el MINECO del Estado Español cuya referencia es FF12015-63794-P 
tiempo presente en el que vale con que todo funcione ${ }^{1}$. La plenitud del mundo inmundo de la tecnociencia consiste precisamente en arrancar y desarraigar al hombre de su tierra. La técnica, así, abunda en el carácter nihilista de nuestro tiempo implantando la época de la voluntad de voluntad ${ }^{2}$ que, al enseñorearse de las cosas, uniformiza y homogeniza todo lo ente a la vez que lo somete. De hecho, aunque no pueda ser imputado al pensamiento filosófico el olvido del ser, la tecnociencia llega al extremo de "expropiarles de la posibilidad de salir alguna vez del olvido del ser" (Heidegger 1994, p. 79). La inmersión en la técnica disminuye las posibilidades de que el hombre considere otro modo de situarse ante el mundo que no sea en términos de dominio y de sometimiento. Mientras más se apodera de nuestro tiempo la mentalidad tecnocientífica que termina por sitiar al propio hombre, más difícil se le hace salir de aquí. Todo está técnicamente determinado y todo ver ha resultado homologado por la mirada de la técnica. Pero donde está el peligro, nace lo que salva, explica Heidegger, recogiendo los versos de Hölderlin, teniendo en cuenta que salvar, entre muchas significaciones, se refiere para Heidegger a aquello que se busca para conducirlo a su esencia. Ya en la primera parte de los Beiträge titulada La resonancia advierte nuestro autor de que en el más completo abandono del hombre por el ser, en el olvido del ser, en el nihilismo perfecto, resuena el eco del ser. La posible emergencia de lo que salva solo es posible porque el hombre, al pensar la esencia de la técnica, recupera su papel de custodio de la verdad y abandona el de mero animal de trabajo, como ha llegado a considerarlo la época actual. No en vano, la visión técnica del mundo ha de rastrearse en los orígenes del pensar de Occidente marcado por el olvido de la aletheia, por la transmutación de la cuestión filosóficamente capital de la verdad. ¿Cómo pensar entonces la técnica moderna para resultar salvo de ella?

En el texto Serenidad, Heidegger lo explica así: es necesario usar la técnica sirviéndose de los objetos de forma apropiada pero manteniéndose libre de ellos. "Podemos decir "sí" al inevitable uso de los objetos técnicos y podemos a la vez decir "no" en la medida en que rehusamos a que nos requieran de modo exclusivo, que dobleguen, confundan y, finalmente devasten nuestra esencia" (Heidegger 1994, pp. 26-27). Esta determinada disposición afectiva (Befindlichkeit) evoca el misterio del ser en el que debe contextualizarse la cuestión de la técnica. Descubrir esa actitud con la que el pensar describe la que tiene que ser la relación del hombre con la técnica puede

1 Así lo explica en la famosa entrevista en Der Spiegel recogida en La autoafirmación de la universidad alemana y otros escritos, 1989.

2 Terminología que aparece fundamentalmente en Heidegger, M.: "Superación de la metafísica" en Conferencias y artículos, Barcelona, Serbal, pp. 63-89. A este respecto, en La época de la imagen del mundo explica que tal uniformidad pasa a ser el instrumento más seguro del dominio completo técnico sobre la tierra. La libertad moderna de la subjetividad se disuelve en la objetividad que le es conforme.

3 Es de sobra conocido, a este respecto, el trabajo de Klaus Held, "La serenidad como virtud de la época técnica". 
revelarnos la actitud crítica que, no dejándose envolver, en el sentido de embaucar y confundir con lo ente, permite al hombre estar en la verdad del ser.

De este modo, la serenidad aparece como una determinada actitud del pensar. Pero al ser una actitud que tiene que ver con el estado de ánimo, el pensar que motiva la serenidad es un pensar distinto al pensar de la tradición de Occidente, al pensar calculante (rechnendes Denken) lo que Heidegger ha llamado el pensar pensante (das besinnliche Nachdenken) (Heidegger 2005). Debemos salir del marco epistemológico que permea toda la filosofía para investigar cómo la serenidad protagoniza una nueva manera de referirnos a cómo el sujeto responde activamente al objeto, esta vez no para hacerse con él, no para conocerlo sino, de alguna manera, para reaccionar ante él. Exactamente la serenidad requiere dar un paso previo a esta división radical del mundo en términos de sujeto-objeto y abordar, entonces, un acceso fenomenológico a la vida en la que el ser humano ya-siempre está, al mundo hacia el que el hombre se encuentra referido per se antes de cualquier ejercicio teórico, a la realidad a la que pertenece y a cuyo conjunto de significados se incorpora.

Si la vuelta a las cosas mismas, de tan alta ventura en la fenomenología, es interpretada como la vuelta a la vida, a la facticidad, al existir y tener que hacerlo, lo que Heidegger deduce es que el hombre puede hacerse cargo auténticamente de esta vida concreta, la suya, mediante una disposición afectiva que abre al ser humano a lo que ninguna teoría puede captar. Pero, puesto que el mundo no se nos aparece como objetividad sobre la que teorizar, la apertura al mundo se lleva a cabo mediante un(os) determinado(s) temple(s) de ánimo que provoca(n) en nosotros determinadas respuestas anímicas. "En cada estado de ánimo (Stimmung), cuando nos sentimos de una manera o de otra, nuestro Dasein se nos revela. De modo que comprendemos el ser aunque nos falte su concepto" (Heidegger 2008, p. 194). Cuando falta el filosofar desde estos Stimmungen, sostiene nuestro autor en los Beiträge, la filosofía se convierte en un mero tableteo de conceptos y palabras ${ }^{4}$.

Pues bien, a esos primeros momentos de su fecunda reflexión, en concreto a la obra Ser y Tiempo (en adelante SyT), queremos referir los orígenes semánticos de este temple de ánimo que es la serenidad, a partir de algunos hitos que nos facilitan la tarea, todos ellos relativos a la pregunta sobre cómo ha de vivir con el mundo ese ente que es el Dasein, el ente privilegiado por poder hacerse la pregunta sobre el sentido del ser en general, el ente al que en su ser le va este ser, el ente cuya existencia consiste precisamente en ser-en-el-mundo. Una vez más, este rastreo semántico de un concepto de la segunda etapa de nuestro autor en alguno de sus primeros trabajos constituye

$4 \quad$ Es la misma experiencia afectiva descrita por Agustín de Hipona como camino que conduce a la cuestión filosófica quid est. Cfr. Xolocotzi, A. "Los temples de la filosofía. Sobre la afectividad histórica del pensar" pp. 51-68. 
una prueba más de nuestras artificiales divisiones sobre el pensamiento de los grandes filósofos ${ }^{5}$.

\section{El encontrarse existiendo del Dasein en el mundo}

Siguiendo la estela de Ser y Tiempo, el ser en del ser en el mundo como existenciario rector del Dasein puede entenderse a la vez como constituido existenciariamente por el encontrarse, el comprender y el habla. Pues bien, ese primer existenciario es el que nos brinda una magnífica oportunidad para enmarcar la cuestión de la serenidad como una de las disposiciones afectivas que explican el volcado existencial del Dasein hacia el mundo. No en vano, el propio encontrarse apunta ya a los estados de ánimo, esto es, a cómo le va a uno en el mundo. Los temples de ánimo son pues constitutivos del Dasein, esto es, constitutivos de cómo se desenvuelve ese Sein que somos cada uno de nosotros en el $D a$, en el ahí en el que nos toca vivir. "El comprender nunca flota en el vacio, sino que se encuentra siempre de alguna manera. El ahí resulta en cada caso abierto o cerrado con igual originalidad por un estado de ánimo” (SyT, p. 305). El Dasein, que es y tiene que ser, se relaciona con el mundo con el que se las ha en modo apertura. Y la serenidad es uno de los modos de estar en esa apertura al mundo responsabilizándose de su existir, siendo consciente de su ser. Nuestra forma de ser en el mundo es una forma específica del Dasein denominada ek-sistencia (apertura en un sentido proyectivo) y concretada por todo un catálogo de estados de ánimo que fijan el cómo del encontrarse del Dasein en el mundo. El estado de ánimo es, entonces, la forma de ser original del Dasein en que este es abierto a sí mismo y al mundo antes de todo ejercicio de la voluntad (en realidad nunca podemos domeñar nuestros estados de ánimo). "El estado de ánimo representa el modo en que yo soy primariamente en cada caso el ente yecto” (SyT, p. 305) ${ }^{6}$. Tengo para mí que el objetivo más expedito de la ontología fundamental en modo analítica existencial es la aclaración de cómo es el existir de ese ente que somos cada uno de nosotros con las cosas y con los otros, cómo es en definitiva el habitar de ese ente que somos cada uno de nosotros entre las cosas y con los otros, cómo es el existir en el mundo. Y que, para el primer caso, para la determinación de la existencia del Dasein con las cosas del mundo la clave está en cómo seguir manteniendo la diferencia ontológica, cómo vivirla y cómo resituar en cada momento lo que supone toda Erschlos senheit: recordemos, el estado de apertura en el que reside el fenómeno más originario de la verdad y, por tanto, del que depende la instauración de ese espacio, de ese plexo de significados (significados que son las operaciones interpretativas por las que el significado del ente tiene que ver con el saber usarlo, saber el para qué del mismso) en el que acontece la mostración de todo ente

5 Este trabajo reproduce y, a la vez, rehace las cuestiones relativas publicadas en Chillón, J. M., Serenidad. Heidegger para un tiempo postfilosófico, Granada, Comares, 2019, pp. 57-73.

6 "El estado de ánimo cae sobre. No viene ni de fuera ni de dentro, sino que como modo del ser en el mundo emerge de este mismo” Heidegger, SyT 130. 
intramundano. Una mostración que, en pro de la claridad a la que aspira la fenomenología, es de algún modo un dejar venir a la presencia.

Todo lo que acontece en el mundo nos incumbe, nos afecta, y la mejor manera de expresar ontológico-existencialmente esta manera de concernirnos queda determinada por las disposiciones afectivas (y muy en especial por la serenidad entendida desde la distancia para con las cosas del mundo, como veremos) y que ahora no deben ser entendidas solo como constituyentes psicológicos. La serenidad, en esta perspectiva fenomenológica, no es una básica y débil manera de estar en el mundo, o quizá una forma solo inicial y vaga de presentarnos ante él, sino muy al contrario, la expresión de la suprema responsabilidad de ser ante la que el Dasein, existiendo, se hace cargo de la carga de su facticidad, esto es, de existir y de tener que hacerlo. Ahora bien, no todo Dasein es consciente de esta forma quasi automática con la que toda disposición afectiva nos pone ante el mundo en el que estamos siendo. Por eso, la fenomenología, aun en esa transformación hermenéutica operada por Heidegger, lleva a cabo el giro, el paso atrás, para tematizar lo que al existir cotidiano pasa desapercibido.

La facticidad de la existencia, este encontrarse afectivamente siendo y teniendo que ser, es lo que Heidegger denomina Geworfener Entwurf. La facticidad ${ }^{7}$ señala pues la condición de estar arrojado, esto es, el nudo hecho de la existencia que así comprendida no es ni un hecho que pueda ser objeto de algún análisis positivista, ni un posible tema para una metódica ciencia objetiva. En este primer carácter ontológico del encontrarse nos topamos con una de las notas características de las primeras determinaciones de la serenidad: el hacerse cargo de la carga que supone la existencia en la que ya siempre se está.

El segundo aspecto que puede servir como un antecedente de la serenidad tiene que ver con cómo la afectividad debe ser desbancada de su connotación psicológica desde el momento en que este encontrarse para nada se refiere al estado reflexivo en el que uno se las tiene que ver con sus vivencias. Para la psicología, los sentimientos, las pasiones, en definitiva todo lo afectivo pertenece a una esfera interna que, de alguna manera, tiñe el mundo externo al que se refiere siguiendo la estela escolástica del quidquid recipitur ad modum recipientis recipitur. Y no solo la psicología, sino que en realidad, toda la teoría del conocimiento con rudimentos en el platonismo viene a disociar en estos términos la realidad. El esquema sujeto cognoscente - objeto conocido parcela lo que existe en una disección fenomenológicamente estéril. De lo que se trata aquí es de observar que todo encontrarse en es la manera, la única manera que tenemos de sabernos existiendo en el contexto en el que estamos y la única que, además, nos concierne, nos incumbe de tal manera que no podemos ser si no es existiendo (afectivamente) en el mundo como un todo. Por ello, la disposición afectiva no solo pone al Dasein mismo ante su responsabilidad de existir, sino que, al comprender la existencia siempre soldada

7 "La facticidad no es la efectividad del factum brutum de algo ante los ojos, sino un carácter del ser del Dasein acogido en la existencia aunque inmediatamente repelido" Heidegger, SyT p. 129. 
al en del ser en el mundo, descubre que la carga lo es también por tener que ser, por tener que encargarse de las otras cosas y de los otros con los que el ser humano existe (Mitsein). El mundo, dirá Heidegger, es aquello donde el Dasein se juega su ser. La serenidad, en este segundo sentido del encontrarse, explicita el cómo de este encargarse de las cosas y de los otros sin que ni cosas ni seres humanos resulten deformados por una tarea subjetiva que en su intento de objetivar objetualiza lo otro y a los otros sin dejar(los) ser lo que son.

El tercer carácter ontológico de la serenidad tiene que ver con cómo, entonces, el mundo, al contar como referencia afectiva, le va al Dasein. Cómo afecta la apertura del mundo al Dasein se explica con la comparecencia de distintos estados de ánimo que avanzan desde el amor, el terror o la indiferencia. Y entonces nos encontramos ante una determinación primaria al mero dirigir la vista propia del conocimiento teórico. Y sin que esto signifique un intento de entregar la ciencia al sentimiento (SyT, p. 131), supone el rechazo a la uniformidad de la mirada especulativa hacia el mundo. En definitiva, el encontrarse del Dasein es la constitución existenciaria de cómo nos entregamos al mundo hasta "dejarnos herir por él" en lo que después Heidegger llamará caída (SyT, p. 132). Y aquí, en esta última determinación del encontrarse, debemos entender la serenidad en el contexto ontológico de la caída. Lo veremos después, pero quizá convenga adelantar que la serenidad no libera al hombre de su existencia esencialmente cadente. La yección del existir es tan constitutiva del ser del Dasein que, de la misma manera que la angustia es la disposición afectiva que asume la muerte como la meta de toda proyección que nunca debe ser obviada (ni por él ni por ninguna hazaña socio-político-tecnológica), la serenidad completa a la angustia en el hacerse cargo del mientras tanto del final adveniente que, aun así, tiene que vivir sin deyectarse, sin tergiversarse ontológicamente. Aunque deberemos matizarlo, podemos pensar que al binomio proyecto yecto le corresponde el par afectivo serenidadangustia. Solo entendiendo el paralelismo correspondiente se verá cómo cada una de las disposiciones insiste respectivamente en las dos dimensiones prístinas de la existencia: ¿Cómo hay que vivir? ¿Cómo asumir que hay que morir? Cuestiones tan coimplicadas que la respuesta a cada una de ellas exige exactamente el planteamiento cuestionador de la otra.

\section{Cuidado y autenticidad como rudimentos teóricos de la serenidad}

"El término Sorge no tiene que ver con la pena, la melancolía, la preocupación por la propia vida que se encuentran ónticamente en todo Dasein. Estas cosas sólo son posibles, así como la incuria y la serenidad porque el ser ahi es ontológicamente comprendido como cura" (SyT, p. 61) ${ }^{8}$. Cuanto más se insista en que lo decisivo para la problemática filosófica es el análisis del existir, más se percibirá la necesidad de pensar

8 Es muy interesante a este respecto el trabajo de García Norro "El cuidado como el ser del Dasein". 
en el cuidado como fenómeno fundamental de nuestra humana existencia. Y en ese contexto debe explicarse la cuestión de la Gelassenheit. En una consideración esencial del Dasein como cura a partir de la cual se despliega la temporalidad como sentido del ser del ente que somos cada uno de nosotros, puede entenderse el valor filosófico de la serenidad como una de las disposiciones afectivas de mayor rendimiento para el pensar que nos queda. Heidegger había definido lo propio del vivir en cuanto vivir en el mundo con el concepto movilidad del trato. Precisamente es a esa movilidad a la que el joven Heidegger denomina Sorge en cuanto un intenso andar en busca de algo, estar ocupado en algo (Aussein auf etwas). Este cuidado, que sustituye a la intencionalidad como relación fundamentalmente teórica con el mundo y que es reconducida al cómo del comportarse respecto a algo, ve al mundo desde las direcciones del cuidado que Heidegger denominará mundos del cuidado: mundo circundante, mundo compartido, mundo del sí mismo. Al entender el cuidado existencialmente como la esencia del ser del Dasein explica por qué la existencia del ser en el mundo no significa existir como las otras cosas que sub-sisten sino que el ek-sistir en cuanto cuidarse pueda tener que ver con: "atender, fabricar, atender los negocios, tomar posesión de algo, impedir, preservar de daños o pérdida” (Heidegger 1982, p. 102). Esta inclinación de la existencia al mundo, esta tendencia intrínseca del existir humano a las cosas resulta explicada por el cuidado. Recordemos que, según Heidegger, el carácter de ser de lo a la mano es la conformidad. Este conformarse ya está transparentando una determinada consideración de la serenidad en cuanto actitud del hombre con el mundo. Ese conformarse (justo el antónimo del deformarse) puede definirse como "dejar ser algo a la mano tal y como es y para lo que es así" (SyT, p. 84). Por cierto que, podemos añadir que la deformación puede ocurrir al modo funcional, al modo formal y lo que, en mi opinión resulta fenomenológicamente más peligroso, al modo del sentido de las cosas. De este modo, el dejar ser del conformarse no implica producción, ni construcción, ni creación, por tanto nada de actividad en cuanto activismo para con el ente sino, al contrario, la pasividad que supone el descubrimiento de lo que ya es ente, permitiendo que, por ese hacerse encontradizo del ente a la mano, el Dasein se conforme en él, es decir, otorgue la libertad necesaria para que no se trastoque lo que es a la mano, lo que es ente. Recordemos que la conformidad o condición respectiva en la traducción de Rivera (Bewandtnis ${ }^{9}$ ) tiene que ver con cómo el ente intramundano se muestra en su modo primario de venir a la presencia, de salir al encuentro. La conformidad explica el nivel de precomprensión condición de posibilidad de toda adecuación con el ente intramundano para poder hacer una cosa u otra. Toda forma de pervertir esta libertad, de tergiversar los espacios donde los entes a la mano pueden ser lo que son, cuenta como una estrategia de cerrazón del Dasein al mundo o de apertura desordenada, como una forma de encubrimiento y oscurecimiento, como una construcción "de las desfiguraciones con las que el Dasein se echa el cerrojo a sí mismo” (SyT, p. 174). A ese descubrir con el que el Dasein existe entre los entes a la mano le es inherente, dice

9 Este Bewandtnis es utilizado por Heidegger en su tesis de habilitación referido al "enfrente" respecto de mi vivencia. El enfrente es un determinado respecto (GA 1, p. 223). 
Heidegger, el desalejar (SyT, p. 161) y en ese momento, el ver en torno al quedar sin ataduras por ese acto distanciador, establece la libertad del Dasein cuyo curarse de no se apropia del ente pudiendo advertir así sus plenas posibilidades de ser.

Esta es la médula heideggeriana de la serenidad: cómo la proximidad de los entes debe ser vivida como distancia; cómo la apropiación con base en la teoría del conocimiento, en la metafísica de Occidente y en la época de la tecnología debe ser reorientada hacia un tipo de desapropiación postmetafísica.

El 'curarse de' puede estar en reposo en sentido del interrumpir la actividad para descansar o del haber acabado la faena. En el reposo no desaparece el curarse de pero sí queda en libertad el ver en torno que ya no es ligado al mundo del obrar (SyT, p. 161)

Así pues, Heidegger reconoce la posibilidad de cuidarse de las cosas o, por el contrario, resultar absorbido por las cosas y deyectarse al nimio nivel del puro estar presente. El declive de la existencia está siempre ahí como posibilidad real para una existencia que es fundamentalmente apertura y posibilidad. Y ahí, en esta constante determinación existencial en la que la libertad se la juega al decidir cómo quiere existir, sobresale la serenidad. La estructura del cuidado es el modo fundamental de ser del Dasein, el modo fundamental de la ek-sistencia que siempre apunta hacia algo que es siempre un ser hacia. Por eso, remarca Heidegger, la estructura de la preocupación se explica como ser-ya-sí-mismo-por-anticipado-cabe-su-mundo (Heidegger 1976, p. 235). Aunque la cura esté esencialmente constituida por la temporalidad, no está determinada cronológicamente en el sentido de que, qua ente, caiga en el tiempo. Pero el hecho de no caer en el tiempo no significa que sea algo extratemporal, sino que la forma de su temporalidad no es en el sentido del tiempo del ahora, tal y como lo ha entendido la tradición. La temporalidad se presenta así como "el fundamento de la posibilidad de la estructura de la preocupación” (Heidegger 1976, p. 410). De aquí dimana la concepción de la temporalidad desde la concepción del futuro como "el tiempo venidero, los ahoras que aun no siendo presentes pero que están viniendo, estos ahoras en cuyo momento en tanto que venidero es algo" (Heidegger 1976, p. 411). El ser de la preocupación es el propio tiempo en tanto que "hacer presente que está a la espera" (Heidegger 1976, p. 413), como es coherente como un ser que es posibilidad de ser. Enseguida descubriremos cómo la temporalidad "en la que reside la unidad original de la estructura de la cura" (SyT, p. 294) está presuponiendo una vivencia del tiempo que obliga a una reordenación de la importancia de los éxtasis temporales (que, según Heidegger, han brotado de una comprensión impropia del tiempo) con una concepción de la temporalidad definida ahora como "advenir presentando que va siendo sido" (SyT, p. 293) teniendo en cuenta que el advenir no se refiere a lo aún no todavía, sino a aquello que estando por venir de alguna manera ya ha sido y está siendo, constituyendo así su existencia propia.

Como la temporalidad refiere al tiempo en cuanto vivido, no en cuanto medido, no en sentido cronológico (que no provocaría otra cosa sino una confusión del ente que es el Dasein con los otros entes intramundanos) parece que ese hacerse cargo del tiempo en cuanto donador de sentido a la existencia humana tiene implicaciones 
decisivas en el modo como el Dasein vive afectivamente su existencia. Precisamente, como ya hemos tratado de exponer en otras ocasiones ${ }^{10}$, los primeros atisbos de la comprensión de la serenidad provienen de cómo Heidegger entiende que el cristianismo primitivo vivió el tiempo de la espera en la venida definitiva del salvador, el tiempo de la parousía. Parece que en esa existencia kairológica y en las recomendaciones paulinas acerca de cómo soportar la tribulación del mundo hasta la segunda venida encuentra Heidegger un preclaro antecedente de la comprensión de la temporalidad esencialmente extática.

El tiempo es originalmente como temporación de la temporalidad que hace posible la constitución de la estructura de la cura. La temporalidad es esencialmente extática. La temporalidad se temporada originalmente desde el advenir. El tiempo original es finito (SyT, p. 297).

En definitiva, en una existencia cuya esencia radica en un constante estado de inconcluso (SyT, p. 215) por el que, al ser un ser de posibilidades, cada realización concreta nunca agota la totalidad de su poder ser, en una existencia abierta y en perpetuo adviento $a$ lo por venir que ha sido (facticidad) y está siendo, sobresale la serenidad como actitud del ser humano para consigo mismo en su relación con el mundo. La serenidad sería así una disposición afectiva para vivir el tiempo con la mirada puesta en una búsqueda de la autenticidad del existir propiamente humano al que no le basta subsistir como los otros entes que son en el tiempo. Y sobre todo, una disposición afectiva para asumir ese precursor estado de resuelto del Dasein que asume su final de muerte y, por tanto, su finitud. Muere el Dasein que se decide a tomar conciencia del fin, pero nunca muere el uno, porque la muerte lo es siempre de alguien. Nunca puede arrebatársele a la muerte el sentido de propiedad, por eso, la existencia impropia no muere. ¿Significa esto que no sabe de la muerte, que vive en la ignorancia del final que le acontecerá como a todos los que son con él? No, en absoluto. Lo que sucede que este saber de la muerte sitúa a esta en una lejanía temporal, en un aún no más acá del cual siempre hay tiempo (SyT, p. 378).

Aristóteles y su concepción de la phronesis parecen ser un claro antecedente de comprensión heideggeriana de la autenticidad del vivir humano. Una ontologización existencial de esta virtud pone a Heidegger sobre la pista de la praxis y de la poiesis como un antecedente fácilmente reconocible de la propiedad (Eigentlichkeit) o impropiedad (Uneigentlichkeit) del Dasein. El mundo cotidiano es el mundo de la poiesis de la vida impropia. Los entes subsisten (Vorhandenheit) y el error griego supone subordinar la manifestación de los entes al logos apofántico. A pesar de lo cual, desde la noción de cuidado que aparece ya en Logik, como Besorgend-Fürsorgende Sorge (cuidado solícito que procura), muestra la indisoluble unidad existente entre praxis y poiesis: la primera en cuanto preocupación del Dasein por su propia existencia, la segunda con

"Ser en el mundo sin ser del mundo. Serenidad y direcciones del cuidado en Heidegger", en concreto, pp. 25-35. 
la inmediata vinculación del ser humano con el mundo, con cuyas cosas establece una primera y básica relación no teórica sino productiva. La preocupación es pues el modo fundamental de ser del ser que en su ser le importa su propio ser.

El ámbito de la praxis es el ámbito de la facticidad que, en tanto cuidado como forma existencial de estar en el mundo, determina su existencia como arrojada, lanzada y obligada a tomar perpetuamente una decisión concerniente a su propio modo de ser que consiste en optar por salir del estado de caída (en una suerte de tendencia antinatural), asumiendo el enfrente de la muerte evitando, de esta manera, que se pierda en la impersonalidad del uno. Cuando el ser humano toma posesión de la muerte y asume su certeza, la vida se hace visible en sí misma, suscribe Heidegger. Y es que es consustancial al ser del hombre en cuanto ser en el mundo, una inclinación a él, una propensión a él que puede terminar con él, en el sentido de que puede absorberlo, en el sentido de que puede arrastrarlo hasta provocar el desmoronamiento ontológico de la vida misma. Es una obra de ingeniería conceptual el delimitar bien la distancia entre el entregarse al mundo del que el ser humano se ocupa, y la constante tentación de afanarse tanto en las cosas del mundo que, al final, se produzca el extrañamiento de la existencia. Por eso la existencia auténtica teniendo que ser en el mundo depende de que ese ser en no implique ni quedarse en las cosas del mundo, confundirse con ellas, ni huir del mundo. La deyección en las cosas y la huida de ellas forma parte de un mismo movimiento constitutivo de la inautenticidad de la existencia que busca seguridades y certezas en algo que es pura posibilidad, pura intemperie, pura apertura. En la posibilidad existencial en la que se juega la autenticidad del ser humano debe comprenderse, pues, la serenidad.

\section{La existencia cadente del Dasein}

Hay una cierta inclinación a quedar absorbido por el mundo en esa continua tendencia de la vida (tendencia a la caída o Verfallenstendenz) a alejarse de sí misma provocando su ruina existencial. La caída, léase en los términos de la cerrazón de lo humano a lo trascendente (a lo porvenir que ya siempre está) se transfigura en el anonimato, en las habladurías o en la irresponsabilidad ante un destino que nunca se asume como propio. La caída es, en los propios términos de Heidegger, la fuga de sí mismo ante sí, la imposibilidad de resolverse ante su propio destino, esto es, la impropiedad. Podríamos pensar que para el hombre se abre la posibilidad de la angustia o de la huida, la posibilidad de asumirse en la finitud radical que a cada momento de autoafirmación y realización personal anuncia el fin inapelable de la muerte, o el ocultamiento de este destino a través de un conjunto de hazañas individuales y sociales que diluyen su responsabilidad y calman la inquietud insoportable del Dasein ante la nada ${ }^{11}$. En definitiva, en la esencia del ser humano, en el

11 Puesto que el encontrarse es la resolución de cómo le va a uno, la angustia, como modo de este encontrarse, responde que le va inhóspitamente: es wird einem unheimlich. Unheimlich es la extrañeza de quien se siente fuera del ámbito familiar como un extraño o incluso un 
cuidado, reside la posibilidad de autentificarse en una existencia que se sabe proyectada $\mathrm{y}$ futuriza, siempre in fieri y provisional, o el peligro del cuidado no esencial para con el propio hombre que acaba diluyendo su ser en el mundo en un ser como las cosas del mundo. La serenidad, precisamente en este contexto del cuidado alimenta la primera refrenando la segunda. De hecho, la serenidad no puede entenderse si no es desde la urgencia que el hombre tiene de resituarse a sí en el mundo, jerarquizando los niveles de relación entre el sí mismo, los otros hombres y las cosas.

¿Qué significa entonces dejarse absorber por el mundo? En realidad, una existencia absorbida por el mundo es, evidentemente, una existencia cadente: una existencia que tiene el carácter del ser perdido en la publicidad del uno (SyT, p. 164). Lo que sucede es que la existencia del ser humano no puede dejar de ser ya siempre caído en el mundo. Así que, hay que pensar cuándo una existencia, que se descubre per se caída, es auténtica, es propia, se hace cargo de sí, y cuándo sucede exactamente al contrario. Ser y Tiempo nos propone una descripción fenomenológica de cómo y hasta dónde puede definirse este anonimato de la existencia que no se hace cargo de sí misma. Pues bien, exactamente, el trinomio (habladurías, avidez de novedades y la ambigüedad) con el que Heidegger especifica la impropiedad de la existencia nos permitirá avistar, por negación de las mismas, algunas de las notas de la serenidad.

La primera tiene que ver con las habladurías (SyT, p. 159) como la forma en la que el Dasein comprende e interpreta cotidianamente. En sentido prefilosófico, todo parece opinable, todo se muestra como abierto, evitando con ello la necesidad de una genuina comprensión. Las habladurías constituyen una especie de opinión pública cotidiana a la que todo le resulta comprensible. En el caso de la avidez de novedades estamos ante la curiosidad que, lejos del juicio ponderado y sosegado, lejos de la contemplación del mundo, está inquieta, excitada y ávida de saber solo por tener sabido. No hay demora ni distancia sino absoluta proximidad; no hay concentración ni reposo sino disipación; no hay quietud sino falta de paradero propia del que es en todas partes y en ninguna, de ahí que la existencia inauténtica sea una existencia desarraigada. Propia de esta existencia cotidiana despersonalizada es la ambigüedad resultante de no poder distinguir la calidad de los discursos o de las interpretaciones; es la ambigüedad resultante del trato con los asuntos que le afectan desde lo que Heidegger denomina publicidad. En esta línea, la existencia cadente en el mundo resulta absorbida por el mundo cuando el Dasein queda gobernado por las habladurías, motivado por la avidez de novedades y determinado por la ambigüedad. Con esto se advierte que la impropiedad de la existencia no significa que el Dasein pueda llegar a dejar de ser en el mundo, que pueda hablarse de una existencia circunstancialmente independiente, sino exactamente al contrario: la existencia impropia significa una existencia tan en el

extranjero y, por tanto, puesto al descubierto, expuesto en cuanto sometido a la intemperie, sin abrigo, sin la seguridad que encuentra uno en su hogar. "En la angustia es el estarsiendo-en-el-mundo el que deviene un absoluto "no-estar-en-casa", el no estar en casa por antonomasia” (Heidegger, Prolegómenos p. 362). 
mundo que termina enfandangándose en el mundo, engolfándose en el ente, dejándose poseer por el mundo y, por tanto, resultando (de)formado por la lógica mundana. Esta caída, ontológicamente hablando, explica la forma existenciaria de relación volcada, consustancialmente relativa del Dasein al mundo. La connotación que aporta el vocablo caída advierte de la insuperable condición mundana y entitativa de un ente a pesar de que no sea como los otros entes intramundanos porque su existencia es ek-sistente, abierta. Lo que sucede es que, mientras la caída expresa una tendencia natural, la proyección supone una tarea de resolución, de conocimiento de sí que exige un esfuerzo que, hasta afectivamente hablando, parece de poca recompensa.

En las entrañas del Dasein acontece la querencia a la existencia mundana, a la subsistencia que se da cuando el ser humano, perdido en el uno, se deja llevar por el natural movimiento tentador que le garantiza la seguridad y la plenitud de todas las posibilidades de su ser (SyT, p. 165). La seguridad, que procede de la existencia impropia, ofrece la tranquilidad y el aquietamiento que aparentemente nos ofrece señales de la serenidad que andamos buscando. Sin embargo, nada más lejos. Heidegger se encarga inmediatamente de advertirnos que el aquietamiento, la seguridad, la sensación de estar a resguardo característica de la impropiedad, no implica ningún tipo de remanso o de descanso, sino que ese reposo es tan aparente que precisamente repercute en un desenfreno que no hace sino incrementar la caída.

Avanza así, en nuestra opinión, la reflexión que va a tener después una impresionante fertilidad en Heidegger: todas las formas sociales, las estructuras políticas, las concepciones científico-tecnológicas son, en cuanto epígonos de la metafísica occidental, manifestaciones de un estar a resguardo, de una tranquilidad que merma toda posible incertidumbre, de una paz aparente que degenera en una forma de existencia desenfrenada marcada por la productividad sin fin, la búsqueda inmediata de resultados y el consumo. Todo ello provoca un derrumbamiento (Absturz) y un despeñamiento existencial cuya gravedad reside en resultar oculta por toda una publicidad que hace de esa forma de vida la única posible. Heidegger habla de derrumbamiento precisamente por lo que supone que el ser humano no solo se libere de la tarea de saberse, de conocerse, sino porque ni siquiera se plantee la posibilidad de tener que hacerlo. Esta propensión a la fuga de sí mismo ante sí (SyT, p. 172) en la que coincide la tendencia natural del que es en el mundo y la propia dinámica del mundo en el que este ente es y tiene que ser, hace imposible un retorno a sí mismo como el que exige la existencia auténtica si no es desde un cambio de acorde en el pensar.

Hablar de serenidad, en este magma, nos obliga no solo a contrariar estas determinaciones (lo que significaría seguir manteniéndose en el contexto del pensar metafísico justificador de la impropiedad de la existencia), sino a abandonar radicalmente este pensar de la cotidianidad del uno no para superarla en una especie de existencia suprahumana, sino para vivirla de otra manera. Mientras la cadencia mundana acontece con las notas de la tentación, el aquietamiento y el extrañamiento, podríamos aventurar que un nuevo pensar, como este en el que sobresale la afección de la serenidad, podría consistir en una vuelta a sí, en un encuentro consigo mismo 
desde las notas respectivas de la indiferencia-disuasión, desde la paz y desde una cierta forma de ensimismamiento ${ }^{12}$.

\section{Conclusión: angustia y serenidad}

La filosofía de la serenidad pretende ser un pensar que toma como punto de partida el mundo al que se accede no por rudimentos teóricos sino por disposiciones emocionales. Recuérdese que el $D a$ del Dasein es la marca del ente que tiene la oportunidad de ser en el mundo o en el ahí en el que vive proyectándose como es propio de su eksistencia desde la Befindlichkeit de la angustia, o en el ahí que vive deyectándose en una subsistencia que determina la impropiedad de una existencia cadente. Sea como sea, la resolución del Dasein que tiene que ser en el mundo y por la que accede a la filosofía depende justamente de que a su ser le importe este su ser y de que tal incumbencia se resuelva afectivamente.

La serenidad, en este sentido, es la disposición afectiva correspondiente al estado de resuelto por la que el ser ahí se sabe como el ente al que le va su ser. Pero, como este su ser es poder ser siempre yecto, la única forma de asumirse resueltamente es conocer que las posibilidades de su ser nunca son absolutas, ni infinitas, sino que radican en la facticidad de su yección que concreta su determinación proyectiva en la realidad de su circunstancia. El estado de resolución es la situación por la que el Dasein sabe cuáles de las posibilidades son las suyas y sobre todo cómo estas posibilidades se encuentran coartadas por la muerte, cuya certeza del acontecer debe conjugarse con la incertidumbre del cuándo. Este saberse de sí, este conocerse en su apertura y, a la vez, este encontrarse arraigado en el mundo en el que está, es lo que debe afrontarse desde la serenidad. Por eso, la serenidad es la actitud del conocimiento personal que no se disuelve en el uno desenfrenado y perdido que rehúsa cualquier forma de tener conciencia de su existencia siempre relativa a la muerte. Frente al ruido de una realidad que resuena constantemente en el ser humano incapacitándole para hacerse cargo de sí, la serenidad, desde esta comprensión del estado de resuelto, advierte del proyectarse

12 Una de las críticas que se le hizo al Heidegger de Ser y Tiempo fue el olvido de la dimensión interpersonal en la determinación de la estructura del Dasein, de sus existenciarios y de su sentido. No falta razón a esta crítica, incluso desde las más fervientes posiciones levinasianas que sitúan a Heidegger como el mentor de la metafísica de la apropiación con su consiguiente puente de plata para una ética de la violencia en una falta de reconocimiento hacia la única filosofía primera posible: la ética de la alteridad. En mi opinión, sin embargo, penetrar más en esta concepción de la serenidad, a pesar de provenir del llamado II Heidegger, y descubrir así su vinculación con el cuidado, puede contribuir a completar aquel sorprendente déficit en la propuesta de 1927. Justo en el momento en el que la serenidad provoca un desplazamiento en los intereses mundanos, justo en el momento en el que la serenidad frena la compulsión tecnológica que convierte hombres y cosas en objetos, justo en ese momento, los otros recobran su lugar conmigo, como otros yo, como otros de los que tengo que ocuparme y preocuparme. La serenidad permite a los otros ser y querer ser. 
silencioso dispuesto a la angustia (SyT, p. 272) que asume su existencia marcada por la contingencia de un ser para la muerte que, habiendo de ser en el futuro, planea sobre nuestro presente (desde el pasado desde el que adviene) en forma de la finitud que precursa la muerte (SyT, p. 276). Y entre el ruido que se oye, se alza la voz que solo dice del Dasein "yo" "yo", en un egoísmo óntico que, como no puede resolverse a ser él mismo, diluye en tal individualismo el poder ser él propio (SyT, p. 290).

En definitiva, el estado de resuelto tal y como aparece en la Analítica Existenciaria de Ser y Tiempo tiene que ver con la serenidad, justo lo que tiene que ver con la libertad: no hay libertad que no sea situada, limitada, concretada y asumida en sus posibilidades más propias. Exactamente aquí también encontramos el nexo que vincula angustia y serenidad: la libertad en cuanto posibilidad ${ }^{13}$ de ser en el mundo. Un mundo que, desde esta toma de posición que suponen tales disposiciones, empieza a quedarse sin sentido, al menos sin el sentido que le otorga al mundo la existencia impropia. La angustia y la serenidad suponen, por tanto, una cierta insignificatividad del mundo y de lo mundano $\mathrm{y}$, por tanto, una reconsideración de las relaciones entre el ser humano y las cosas entre las que y con las que tiene que ser. No es posible una existencia fundada en las cosas de las que ha de curarse. Es imposible que pueda hablarse de proyecto desde aquí. Acontece de alguna manera la nada del mundo, no porque nos enfrentemos a un mundo en el que lo ante los ojos resulte ausente, sino porque esas cosas que existen no ofrecen absolutamente ninguna conformidad, con lo cual la apertura del Dasein no encuentra algo en el mundo en lo que pueda comprenderse. El movimiento que le sucede a la angustia y a la serenidad es justamente la vuelta a sí ante la insoportable desilusión de lo mundano. Quedando libre de las ataduras del mundo, se descubre libre para la proyección de sus posibilidades más propias. La nada del mundo no anonada al Dasein, sino que invita a una resemantización del sí mismo en el mundo. En este sentido, el volverse a sí, el recogerse de la disipación y de la natural querencia al mundo (con su consiguiente degeneración a lo mundano), el dejar de considerar el mundo como un conjunto de objetos que gestionar y que producir, exige la distancia para con las cosas, el paso atrás sobre lo obvio, la pregunta sobre aquello que pasa desapercibido por ser lo más evidente.

La serenidad completa la angustia que sobreviene al Dasein cuando este se descubre abierto hacia un futuro que inapelablemente le es propio: la muerte. Angustia y serenidad son, en nuestra opinión, las dos actitudes que representan la paradójica

13 En S. Kierkegaard es evidente el nexo entre libertad y angustia precisamente definida como el vértigo de la libertad. La posibilidad, llegará a escribir, es la más pesada de todas las categorías. "El hombre no podría angustiarse si no fuese una bestia o un ángel. Pero es una síntesis y por eso puede angustiarse. Es más, tanto más perfecto será el hombre cuanto mayor sea la profundidad de su angustia. Pero esto no hay que entenderlo en el sentido de una angustia por algo exterior, por algo que está fuera del hombre, sino de tal manera que el hombre mismo sea la fuente de la angustia” (Kierkegaard, p. 300). 
existencia del ser humano ${ }^{14}$. El Dasein descubre su tiempo como el tiempo del mientras tanto ante la muerte de la que tiene que hacerse cargo y, por tanto, se descubre a sí mismo como no siendo un ente más cabe los entes, sino aquel ente ocupado por el ser en cuya pregunta le va su propio ser ${ }^{15}$. Por ser cabe los entes, nunca puede rebasar el nivel de la mundanidad en la que está. Por irle el ser, ya siempre está en el contexto de la pregunta, ya siempre tiene una precomprensión ontológica del sentido del ser en general, ya siempre se sabe como no agotado en el aparecer sino proyectado hacia sus posibilidades. Esta doble faz ontológica es la que resume el ser del Dasein como proyecto yecto. De modo que la angustia existencial con la que el Dasein palpa la nada que le aproxima a los dominios del ser no tiene por qué llevar acoplada una actitud ansiosa o atribulada ante el final inminente, sino muy al contrario, la paz, el sosiego o la tranquilidad que no trata de compensar el fin adveniente con ningún tipo de placebo ontológicamente degradante. La serenidad expresa mejor que nada la autenticidad de la existencia que al descubrir su esencia como cura y su sentido como Zeitlichkeit no huye del pensar para refugiarse en el mundo, para cobijarse en el puro presente, para deyectarse en el infranivel de las cosas.

\section{Referencias bibliográficas}

Chillón, José Manuel (2018), "Ser en el mundo sin ser del mundo. Serenidad y direcciones del cuidado en Heidegger", Pensamiento. Revista de investigación e información filosófica, vol. 74 (281): 20-44.

(2016), "Heidegger: La paradójica existencia del Dasein en el mundo", Differenz. Revista Internacional de Estudios Heideggerianos y sus derivas contemporáneas 3: 18-33.

(2019), Serenidad. Heidegger para un tiempo postfilosófico. Granada: Comares.

García Norro, Juan J. (2015), “El cuidado como el ser del Dasein”, en R. Rodríguez, coord., Ser y Tiempo de Heidegger: Un comentario fenomenológico. Madrid: Tecnos, pp. 167-197.

Grondin, Jean (2003), "Heidegger und Agustin. Zur hermeneutischen Wahrheit", en E. Richter, ed., Die Frage nach der Wahrheit. Frankfurt: Klostermann, pp. 150-172.

Heidegger, Martin (1994), Conferencias y artículos. Barcelona: Serbal.

14 Cfr. J. M. Chillón, "Heidegger: La paradójica existencia del Dasein en el mundo”, pp. 18-33.

15 Por cierto, con claras resonancias de las Confesiones agustinianas: "mihi quaestio factus sum” (Conf. X, 33). Tanto Agustín como Heidegger - explica Grondin-coinciden en situar lo genuino de la existencia humana en su capacidad para preguntar. Una existencia que, fenomenológicamente descrita y fácticamente considerada, resulta precisamente estructurada por la pregunta. Cfr. J. Grondin, pp. 150-172. 
(2006), Prolegómenos para una historia del concepto de tiempo. Madrid: Alianza Editorial.

(1977), Sein und Zeit. Frankfurt am Main: Vittorio Klostermann. Se cita la edición y traducción castellana de José Gaos (2002), Ser y Tiempo. Madrid: RBA. (2008), Kant y el problema de la metafísica. México: FCE.

(1982), Ontologie. Hermeneutik der Faktizität. Frankfurt am Main: Vittorio Klostermann.

(1976), Logik. Die Frage nach der Wahrheit. Frankfurt am Main: Vittorio Klostermann.

(2005), Qué significa pensar. Madrid: Trotta.

(1989), "Entrevista en Der Spiegel", La autoafirmación de la universidad alemana y otros escritos. Madrid: Tecnos.

Held, Klaus (2012), "La serenidad como virtud de la época técnica", Ética y política en perspectiva fenomenológica. Bogotá: Siglo del hombre editores, pp. 235252.

Kierkegaard, Sören (2016), El concepto de angustia. Madrid.

Xolocotzi, Angel (2016), "Los temples de la filosofía. Sobre la afectividad histórica del pensar", en R. Gibu y A. Xolocotzi, eds., Temple de ánimo y filosofía. Consideraciones heideggerianas sobre la afectividad. México: Universidad Autónoma de México, pp. 51-68. 